\title{
Mortality study of nickel platers with special reference to cancers of the stomach and lung, 1945-93
}

\author{
D Pang, D C L Burges, T Sorahan
}

\begin{abstract}
Objectives-To re-examine mortality patterns in a cohort of nickel platers with no history of chromium plating.

Methods-All 284 men first employed by the company in 1945-75 with a minimum employment of three months in the nickel plating department were identified. Workers who had worked in the chromium plating or nickel/chromium plating departments were excluded. Standardised mortality ratios (SMRs), P values, and $95 \%$ confidence intervals were calculated. Poisson regression was used to carry out statistical modelling of mortalities within the cohort (internal standard). Four variables were considered to have the potential to influence mortality within the cohort: attained age (age at follow up or age at death), year of starting nickel work, period of follow up (measured from the first period of work with nickel exposure), and duration of exposure to nickel.
\end{abstract}

Results-The only significant difference between observed and expected numbers, when investigated by site of cancer and by broad non-cancer groupings, was that for stomach cancer (observed eight, expected 2.49, SMR 322).

Conclusions-The study provides only weak evidence that nickel plating is associated with an excess risk of stomach cancer. This cohort of nickel platers does not seem to have experienced any discernible risk of occupational lung cancer. Other studies of nickel platers rather than nickel/chromium platers would be useful.

Occupational Health, University of

Birmingham,

Edgbaston,

Birmingham B15 2TT

D Pang

T Sorahan

406 Quinton Road

West, Quinton,

Birmingham B32 1QG

D C L Burges

Correspondence to:

D Pang, Institute of

Occupational Health

University of Birmingham,

University of Birmingham,

Accepted 11 July 1996
(Occup Environ Med 1996;53:714-717)

Keywords: nickel; electroplating; cancer

Nickel, in the form of various alloys and compounds, has been widely used in industry for over 100 years. Several million workers worldwide are exposed to airborne fumes, dusts, and mists containing nickel and its compounds and a recent evaluation of carcinogenic risk carried out by an International Agency for Research on Cancer (IARC) Working Group concluded that, on the basis of available biological, experimental, and epidemiological data, nickel compounds are carcinogenic to humans. ${ }^{1}$ The reviewed epidemiological studies indicated excess risks of lung and nasal cancers for several cohorts exposed to nickel. Most of these studies were concerned with nickel mining, smelting, and refining industries. In the three studies concerned with nickel plating, ${ }^{2-4}$ the carcinogenicity of nickel exposure was difficult to assess, due, in part, to possible confounding effects of chromium exposure (two of these studies referred to nickel/chromium platers). Similar problems are associated with another small study. ${ }^{5}$

The present report examines mortality patterns in a cohort of nickel platers with no history of chromium plating. Initial findings from the cohort were reported by Burges. ${ }^{4}$ There was no excess of deaths from respiratory cancers but an increased standardised mortality ratio (SMR) was shown for cancer of the stomach. Sixteen years of follow up data have now been added to the study files. The plating factory in Birmingham, West Midlands, United Kingdom, was once the largest user of nickel in Europe and produced bumpers, window winding mechanisms, door handles, and many other car accessories. (It supplied Morris Motors with the first bumpers to be fitted to a popular British car as standard equipment.) At the peak of its operations, 35000 plated bumpers were produced each week.

The process of plating bumpers with nickel was carried out in stages. Firstly, the bumpers were formed from mild steel. They were then polished, degreased with trichloroethylene, and taken to the nickel plating department where the bumpers were first dipped in a caustic soda bath and then taken to a cold water swill. They were then "etched" in a strong acid bath and again taken to a cold water swill. Only then were they plated with nickel in the nickel baths (electrolytic process).

The nickel plating department was the only department where workers could be exposed to nickel compounds. In 1945, all nickel plating was carried out in manual baths and there was no local exhaust ventilation. In 1956, some semiautomatic baths were introduced, and by 1961, all the manual baths had been removed. The semiautomatic baths used air agitation to assist with the plating process and this would 
have encouraged the release of bath electrolyte into the workplace environment. Such releases were dealt with by local exhaust ventilation, which was introduced with the new baths. Workers handled nickel salts including nickel chloride $\left(\mathrm{NiCl}_{2} \cdot 6 \mathrm{H}_{2} \mathrm{O}\right)$ and nickel sulphate $\left(\mathrm{NiSO}_{4} .6 \mathrm{H}_{2} \mathrm{O}\right)$. The principal source of air contamination was a mist of nickel sulphate or nickel chloride.

\section{Materials and methods \\ MATERIALS}

A revised cohort was defined as all 284 men first employed by the company in 1945-75 with a minimum employment of three months in the nickel plating department. (The original cohort analysed by Burges had no minimum employment.) Workers who had worked in the chromium plating or nickel/chromium plating departments continue to be excluded. ${ }^{4}$

Data for each study subject consisted of identifying particulars, job history, and vital status. Job histories for each worker comprised dates of starting and ending work in different departments. Job histories were abstracted from work engagement cards held in the factory personnel records. Each period of work in the nickel plating department was classified under one of five headings: nickel bath workers, jiggers and unjiggers, inspectors, material handlers, and a miscellaneous category.

The vital status of each study subject on the closing date of the study (31 December 1993) was obtained from the National Health Service Central Register (NHSCR) of the Office of Population Censuses and Surveys

Table 1 Vital status at closing date of study (31 December 1993)

\begin{tabular}{lc}
\hline Vital status & $n(\%)$ \\
\hline Traced alive & $150(52 \cdot 8)$ \\
Emigrated & $10(3 \cdot 5)$ \\
No trace & $21(7 \cdot 4)$ \\
Died, cause known & $102(35 \cdot 9)$ \\
Died, cause unknown & $1(0 \cdot 4)$ \\
Total & $284(100 \cdot 0)$ \\
\hline
\end{tabular}

*Includes four deaths occurring after the age of 85 years; these deaths are not listed in table 2.

Table 2 Nickel platers: cancer mortality and mortality from other causes, 1945-93

\begin{tabular}{llrrrr}
\hline Cause & $I C D-8$ & Obs & Exp & SMR & $95 \% C I$ \\
\hline All neoplasms: & $140-239$ & 28 & $26 \cdot 16$ & 107 & $71-155$ \\
$\quad$ Stomach & 151 & 8 & $2 \cdot 49$ & $322^{\star \star}$ & $139-634$ \\
Large intestine & 153 & 1 & $1 \cdot 66$ & 60 & $2-336$ \\
Rectum & 154 & 2 & $1 \cdot 16$ & 172 & $21-622$ \\
Pancreas & 157 & 1 & $1 \cdot 09$ & 91 & $2-509$ \\
Larynx & 161 & 1 & $0 \cdot 25$ & 399 & $10-2222$ \\
Lung & $162-163$ & 11 & $10 \cdot 16$ & 108 & $54-194$ \\
Prostate & 185 & 1 & $1 \cdot 59$ & 63 & $2-351$ \\
Bladder & 188 & 1 & $0 \cdot 51$ & 102 & $3-567$ \\
Brain & $191-192$ & 1 & $0 \cdot 62$ & 162 & $4-900$ \\
Non-cancers: & & & & & \\
Circulatory system & $390-458$ & 45 & $46 \cdot 07$ & 98 & $71-131$ \\
Respiratory system & $460-519$ & 16 & $10 \cdot 46$ & 153 & $87-248$ \\
Digestive system & $520-577$ & 4 & $2 \cdot 53$ & 158 & $43-405$ \\
Genitourinary system & $580-629$ & 1 & $1 \cdot 17$ & 85 & $2-475$ \\
Accidents & $800-949$ & 3 & $2 \cdot 34$ & 128 & $26-375$ \\
Suicide & $950-959$ & 0 & $1 \cdot 10$ & 0 & $0-334$ \\
All causes & & 99 & $94 \cdot 67$ & 105 & $85-127$ \\
\hline
\end{tabular}

Sites of cancer for which there were no observed deaths and for which the expectation was less than 1.0 are not shown in the table. ICD-8 codes (and expectations) were as follows: 140 $(0.01), 141(0.09), 142(0.03), 143-145(0.08), 146-149(0.17), 150(0.87), 152(0.05), 155$ $(0.02), 158(0.05), 159(0.08), 160(0.05), 172-173(0.23), 186(0.07), 189(0.50), 200,202$ $(0 \cdot 51), 201(0 \cdot 17), 204-207(0 \cdot 60)$.
(OPCS). Details of workers for whom insufficient information was available for tracing by the OPCS were sent to the central offices of the Department of Social Security (DSS) for tracing by National Insurance numbers. For those who had died, a death certificate was obtained with the underlying cause of death coded to the contemporaneous revision of the International Classification of Diseases (ICD). Table 1 shows the results of follow up. Vital status was ascertained for $89 \%$ of the cohort, and cause of death was ascertained for all but one of the identified deaths. Smoking histories were not available.

\section{METHODS}

External standard: standardised mortality ratios Expectations were calculated from serial mortalities for England and Wales applied to similarly defined arrays of person-years at risk generated by the data. Men entered the person-years at risk at the end of the first three months of work in the nickel plating department and left the person-years at risk on the date of death, date of embarkation, date last known alive, or the closing date of the study, whichever was the earlier. All subjects were censored on reaching their 85th birthdaythat is, they made no further contributions to expected or observed numbers past this age. The rationale for this procedure has been supplied previously. ${ }^{6}$ Standardised mortality ratios, $\mathrm{P}$ values, and $95 \%$ confidence intervals (95\% CIs) were calculated from expected values to three places of decimals; deaths were assumed to have a Poisson distribution. Significance tests were two tailed.

\section{Internal standard: Poisson regression}

Poisson regression was used to carry out statistical modelling of mortalities within the cohort (internal standard). Four variables were considered to have the potential to influence mortality within the cohort: attained age (age at follow up, or age at death), year of starting nickel work, period of follow up (measured from the first period of work with nickel exposure), and duration of exposure to nickel. Attained age, period of follow up, and duration of work exposed to nickel are time dependent variables and the analysis allowed, therefore, for subjects to contribute personyears at risk to contemporaneous categories.

The DATAB and AMFIT programs of the EPICURE $^{7}$ computer package were used to provide both person-years at risk and numbers of deaths for causes of interest for all combinations of all levels of the above variables and to carry out statistical modelling by means of Poisson regression. ${ }^{8}$ The purpose of the modelling was to establish whether the mortality of the study cohort could be described easily by variables such as attained age and year of starting nickel work or whether duration of work with nickel exposure was an important variable in describing patterns of mortality.

In constructing the models, levels were combined to ensure that for each variable, at least one death was observed in each level as entered into the analysis. The first level of 
Table 3. Mortality from stomach cancer and lung cancer in nickel platers by period from first employment with exposure to nickel, and by type of first occupation with exposure to nickel, 1945-93

\begin{tabular}{|c|c|c|c|c|c|c|c|c|}
\hline \multirow[b]{2}{*}{ Variable with levels } & \multicolumn{4}{|c|}{ Stomach cancer } & \multicolumn{4}{|c|}{ Lung cancer } \\
\hline & Observed & Expected & $S M R$ & $\begin{array}{l}P \text { value } \\
\text { for trend }\end{array}$ & Observed & Expected & $S M R$ & $\begin{array}{l}\text { P value } \\
\text { for trend }\end{array}$ \\
\hline \multicolumn{9}{|l|}{$\begin{array}{l}\text { Period from first employment with } \\
\text { exposure to nickel }(y) \text { : }\end{array}$} \\
\hline $0-9$ & 2 & 0.42 & 476 & & 2 & $1 \cdot 30$ & 153 & \\
\hline $10-19$ & 2 & 0.65 & 308 & & 1 & 2.54 & 39 & \\
\hline $20-29$ & 3 & 0.73 & 409 & & 4 & $3 \cdot 21$ & 125 & \\
\hline $30-39$ & 1 & 0.50 & 199 & & 2 & $2 \cdot 31$ & 87 & \\
\hline$\geqslant 40$ & 0 & $0 \cdot 18$ & 0 & & 2 & $0 \cdot 79$ & 254 & \\
\hline Total & 8 & $2 \cdot 49$ & $322^{\star \star}$ & & 11 & $10 \cdot 16$ & 108 & \\
\hline & & & & 0.67 & & & & 0.53 \\
\hline \multicolumn{9}{|l|}{ First occupation with exposure to nickel: } \\
\hline $\begin{array}{l}\text { Nickel bath workers }(n=112) \\
\text { Jiggers and unjiggers }(n=102)\end{array}$ & $\begin{array}{l}3 \\
1\end{array}$ & $\begin{array}{l}1.24 \\
0.55\end{array}$ & $\begin{array}{l}242 \\
181\end{array}$ & & $\begin{array}{l}6 \\
2\end{array}$ & $\begin{array}{l}\cdot 21 \\
2 \cdot 32\end{array}$ & $\begin{array}{r}115 \\
86\end{array}$ & \\
\hline Inspectors $(n=14)$ & 1 & $0 \cdot 16$ & 642 & & 0 & 0.60 & 0 & \\
\hline Material handlers $(n=50)$ & 2 & 0.50 & 403 & & 2 & $1 \cdot 87$ & 107 & \\
\hline Miscellaneous $(n=6)$ & 1 & 0.04 & 2500 & & 1 & $0 \cdot 17$ & 588 & \\
\hline
\end{tabular}

$\star \star P<0.01$

Table 4 Relative risks for all causes of death, stomach cancer, lung cancer, and non-malignant diseases of the respiratory system by duration of employment with exposure to nickel *

\begin{tabular}{|c|c|c|c|c|}
\hline $\begin{array}{l}\text { Duration of nickel- } \\
\text { exposed employment }(y)\end{array}$ & $N$ & $R R+(95 \% C I)$ & $R R \ddagger(95 \% C I)$ & $\begin{array}{l}\text { Person-years } \\
\text { at risk }\end{array}$ \\
\hline \multicolumn{5}{|l|}{ All causes: } \\
\hline$<1.0$ & 57 & $1 \cdot 00$ & 1.00 & $3949 \cdot 4$ \\
\hline$\geqslant 1 \cdot 0$ & 42 & $1.03(0.69$ to 1.54$)$ & $1.09(0.72$ to 1.64$)$ & $2979 \cdot 2$ \\
\hline \multicolumn{5}{|l|}{ Stomach cancer: } \\
\hline$<1.0$ & 3 & 1.00 & 1.00 & $3949 \cdot 4$ \\
\hline$\geqslant 1.0$ & 5 & $2.18(0.52$ to 9.15$)$ & $2.61(0.60$ to 11.33$)$ & $2979 \cdot 2$ \\
\hline \multicolumn{5}{|l|}{ Lung cancer: } \\
\hline$<1.0$ & 6 & 1.00 & 1.00 & $3949 \cdot 4$ \\
\hline$\geqslant 1 \cdot 0$ & 5 & $1.21(0.37$ to 3.97$)$ & $1.25(0.36$ to 4.33$)$ & $2979 \cdot 2$ \\
\hline \multicolumn{5}{|c|}{$\begin{array}{l}\text { Non-malignant diseases of } \\
\text { respiratory system: }\end{array}$} \\
\hline $\begin{array}{l}\text { respiratory system: } \\
<1.0\end{array}$ & 8 & 1.00 & 1.00 & $3949 \cdot 4$ \\
\hline$\geqslant 1.0$ & 8 & $1.40(0.52$ to 3.74$)$ & $1.59(0.58$ to 4.36$)$ & $2979 \cdot 2$ \\
\hline
\end{tabular}

^For ICD-8 codes, see table 2

tAdjusting for age $(<55,55-59,60-64,65-69,70-74$, and 75-84 years). For stomach cancer, the following categories were used: $<50,50-59,60-69$, and $70-84$.

‡Adjusting for age, period of follow up $(<10,10-19,20-29,30-39$, and $\geqslant 40$ years), and year of starting nickel work (1946-55, 1956-65, and 1966-75).

cumulative exposure was used as a reference. Risks for the second level of cumulative exposure were calculated relative to the risk in the reference category.

\section{Results}

Table 2 shows observed and expected numbers of deaths by site of cancer and by broad non-cancer groupings. The only significant difference between observed and expected numbers was that for stomach cancer (observed eight, expected 2.49, SMR 322, 95\% CI 139-634). Mortality from lung cancer was close to expectation (observed 11, expected 10.16, SMR 108, 95\% CI 54-194). Numbers of deaths for other site specific cancers were small. Mortality from non-malignant diseases of the respiratory system was above expectation although the difference between observed and expected numbers was not significant (observed 16, expected 10.46, SMR $153,95 \%$ CI 87-248). Mortality from diseases of the circulatory system was close to expectation (observed 45, expected 46.07, SMR 98, 95\% CI 71-131).

Table 3 shows observed and expected numbers of deaths from stomach cancer and lung cancer by period from first employment with nickel exposure. The SMRs were similar for early $(<20)$ and later $(\geqslant 20)$ years of follow up. In a separate analysis (not shown) there was little difference in SMRs for stomach and lung cancer for two entry cohorts (stomach cancer: year of hire 1945-61, SMR $=305$ (observed six), year of hire 1962-75, SMR = 385 (observed two); lung cancer: year of hire 1945-61, SMR = 103 (observed eight), year of hire 1962-75, SMR $=125$ (observed three)). The table also shows observed and expected numbers of deaths for stomach cancer and lung cancer by first occupation exposed to nickel. Because of small numbers, no importance can be attached to any of the differences found.

Table 4 shows relative risks calculated by Poisson regression for all causes, lung cancer, stomach cancer, and non-malignant diseases of the respiratory system by duration of exposed work. Relative risks were adjusted either with attained age only (the left hand half of the table) or with attained age, period of follow up, and year of starting nickel work (right hand half of the table). None of the relative risks approached significance. Relative risks adjusted for attained age only were similar to those calculated with further adjustment.

\section{Discussion}

The study provides no evidence that nickel plating is associated with excess risks of lung cancer. The overall SMR was very close to expectation, the pattern of SMRs by period 
from first employment with nickel exposure was not indicative of any occupational role and risks for study subjects who had been exposed for one or more years were similar to those for study subjects with shorter periods of exposure. It was not possible to assess the influence of smoking habits on these findings.

The study provides only weak evidence that nickel plating is associated with an excess risk of stomach cancer. The overall SMR was significantly raised although the pattern of SMRs by period since first employment with nickel exposure was not indicative of any occupational role. (Some of the overall excess could be explained by the regional and social class composition of the cohort.) The point estimates for the risk of mortality in those study subjects who were exposed to nickel for one or more years were more than double those for study subjects with shorter periods of exposure but the confidence intervals for these point estimates were very wide; an underlying risk of unity could not be excluded.

The study is limited by its modest size and by unusually short (compared with other occupational cohorts) periods of exposed work (mean 2.10 years, median 0.86 years); the work was unpopular and there was a rapid turnover of staff. However, most of the cohort $(56.7 \%)$ were first employed in the period 1945-61 when occupational nickel exposures would have been higher than those found currently in the industry. Unfortunately, occupa- tional hygiene data relating to nickel exposure are not available.

Confident interpretation of the lung cancer findings is not possible but this cohort of nickel platers does not seem to have experienced any discernible risk of occupational lung cancer. Other studies of nickel platers rather than nickel/chromium platers would be useful.

We thank Joyce Secker for abstraction of the original data and Ivy Peck for double checking the current study files. We thank the Office of Population, Censuses, and Surveys and the Department of Social Security for tracing the study cohort. We acknowledge the earlier involvement of the Health and Safety Executive (HSE) in establishing this cohort and thank the HSE for facilitating access to the study files.

1 International Agency for Research on Cancer. IARC Monogaphs on the evaluation of carcinogenic risks to humans,

2 Sorahan T, Burges DCL, Waterhouse JAH. A mortality study of nickel/chromium platers. Br F Ind Med 1987; 44:250-8

3 Silverstein $M$, Mirer F, Kotelchuck D, Silverstein B, Bennette $M$. Mortality among workers in a die-castin and electroplating plant. Scand $\mathcal{f}$ Work Environ Health 1981;7:156-65.

4 Burges DCL. Mortality study of nickel platers. In: Brown SS, Sunderman FW, eds, Toxicology of nickel. London: Academic Press, 1980:15-8.

5 Horiguchi S, Morinaga K, Endo G. Epidemiological study of mortality from cancer among chromium platers. Asia of mortality from cancer among ch
Pac ₹ Public Health 1990;4:169-74.

6 Sorahan T, Cooke MA. Cancer mortality in a cohort of United Kingdom steel foundry workers: 1946-85. $\mathrm{Br} f$ Ind Med 1989;46:74-81.

7 Epicure. Seattle, USA: Hirosoft International Corporation, 1988.

8 Breslow NE, Day NE. Statistical methods in cancer research, vol II. The design and analysis of cohort studies. Lyon: International Agency for Research on Cancer, 1987. (IARC Sci Publ No 82.) 